\title{
EHMTI-0304. Headache determines quality of life in idiopathic intracranial hypertension
}

\author{
A Sinclair ${ }^{1 *}$, Y Mulla ${ }^{1}$, K Markey $^{1}$, J Mitchell ${ }^{1}$, S Patel $^{2}$ \\ From 4th European Headache and Migraine Trust International Congress: EHMTIC 2014 \\ Copenhagen, Denmark. 18-21 September 2014
}

\section{Introduction}

No previous studies have assessed quality of life (QoL) in idiopathic intracranial hypertension (IIH) associated with a therapeutic weight loss. Our previously published prospective cohort study confirmed that weight loss significantly reduced intracranial pressure (ICP) and treated chronic active adult IIH.

\section{AIMS}

Evaluate if QoL improved following treatment of IIH achieved through weight loss. Additionally, evaluate the relationship between QoL and changes in clinical outcome measures (body mass index (BMI), ICP (lumbar puncture), papilloedema (optical coherence tomography retinal nerve fibre layer thickness), automated perimetry (Humphrey visual field 24-2), LogMar visual acuity as well as headache severity (diarised verbal rating scale $0-10$ ) and disability (headache impact test-6).

\section{Method}

QoL was assessed using the short form 36 questionnaire (SF-36) before and after a dietary intervention and compared to changes in clinical outcomes. Baseline QoL was also compared to a control cohort.

\section{Results}

At baseline, SF-36 scores were worse in IIH group compared to an age-matched population. Following therapeutic weight loss, with reduction of ICP ( $p<0.001)$, SF-36 significantly improved (8 out of 11 domains). Despite a significant improvement with therapeutic weight loss, the following were not associated with enhanced quality of life: ICP, papilloedema, automated perimetry, visual

\footnotetext{
${ }^{1}$ Neurotrauma and Neurodegeneration School of Clinical and Experimental Medicine College of Medical and Dental Sciences, University of Birmingham, Birmingham, UK

Full list of author information is available at the end of the article
}

acuity and BMI. The only variables that significantly correlated with improved QoL were headache severity and disability, $\mathrm{p}<0.001$.

\section{Conclusion}

QoL significantly improved in IIH following therapeutic weight loss with reduction in ICP. Improvement in headache was the only factor that correlated with enhanced QoL. Effective headache management is a vital determinant of QoL in IIH.

No conflict of interest.

\section{Authors' details}

${ }^{1}$ Neurotrauma and Neurodegeneration School of Clinical and Experimental Medicine College of Medical and Dental Sciences, University of Birmingham, Birmingham, UK. ${ }^{2}$ Birmingham Clinical Trials Unit, University of Birmingham, Birmingham, UK.

Published: 18 September 2014

doi:10.1186/1129-2377-15-S1-C57

Cite this article as: Sinclair et al.: EHMTI-0304. Headache determines quality of life in idiopathic intracranial hypertension. The Journal of Headache and Pain 2014 15(Suppl 1):C57.

Submit your manuscript to a SpringerOpen ${ }^{\odot}$ journal and benefit from:

- Convenient online submission

- Rigorous peer review

- Immediate publication on acceptance

- Open access: articles freely available online

- High visibility within the field

- Retaining the copyright to your article

Submit your next manuscript at $\boldsymbol{~ s p r i n g e r o p e n . c o m ~}$

\section{SpringerOpen ${ }^{\odot}$}

C 2014 Sinclair et al; licensee Springer. This is an Open Access article distributed under the terms of the Creative Commons Attribution License (http://creativecommons.org/licenses/by/2.0), which permits unrestricted use, distribution, and reproduction in any medium, provided the original work is properly cited. 